\title{
From Inter- Disciplinarity to Trans Disciplinarity in the Academic Translation Teaching
}

\author{
Mehmet Cem Odacıŏglu (Corresponding author) \\ Department of Translation Studies, Sakarya University, Turkey \\ Şaban Köktürk \\ Department of Translation Studies, Sakarya University, Turkey
}

Received: 08-12-2015

Accepted: 05-01-2016

Published: 01-04-2016

doi:10.7575/aiac.ijclts.v.4n.2p.3

URL: http://dx.doi.org/10.7575/aiac.ijclts.v.4n.2p.3

\begin{abstract}
Translation Studies has been accepted as an academic discipline as of the second half of the Twentieth Century and since then, many translation theories have been developed by the translation scholars or linguists. These theories can be useful for translators in the translation process and in the determination of the function of the translation. Additionally, they can synchronically and diachronically contribute to the comparison of translation products. As a continuous developing discipline, Translation Studies has first integrated itself with linguistics, science of philosophy, literature studies, sociology, history and cultural studies. Thus, the translation teaching that first focused on language teaching has gained an inter-disciplinary status. However after the millennium, it is thought that there is also a journey from interdisciplinary aspects of Translation Studies and translation teaching to trans-disciplinarity. Because Translation Studies has now extended its scope into Information \& Communication Technologies, computational linguistics, computer engineering, computer programming and so forth. Therefore, the current translation teaching must be done taking into account this reality. Hence, in this study, transdisciplinary aspects of the translation teaching are discussed in the context of new areas of study by analyzing the technology based translation courses which are found in translation curricula at Boğaziçi, Illinois and Western Sydney Universities.
\end{abstract}

Keywords: Discipline, Interdisciplinarity, Interdisciplinary, Transdiciplinarity, Transdisciplinary, Translation Teaching

\section{Introduction}

Before the translation phenomena turned into a scientific field with the seminal paper called "The Name and Nature Translation Studies" by Holmes (1972), the translation activity was mostly being offered as a way of teaching a foreign language in the classroom. However, Holmes, in his paper drew a map under the name of Translation Studies which explains in detail theoretical, practical and applied aspects of the translation phenomena, Later, the map was developed or discussed by other translation scholars (e.g. Toury, Vandepitta, etc.). In parallel with this, the map was extended into new sub-branches over time as the new translation fields appeared due to the shifting requirements of the translation market.

In connection with thisthe change and the update of the Translation Studies map is generally triggered by the presence of Information \& Communication Technologies, a new subfield of linguistics called computational linguistics, other technological developments and the birth of disciplines such as computer engineering, computer programming and so forth. The reason is that the new technologies and disciplines contribute to the translation process by facilitating it and as a result the way of translating has radically changed, so has the duty of translators. Therefore, the translator training designed for the translation curricula must be refreshed and offered in accordance with these developments. According to Yazic1, Translation Studies has to date encountered with new terms and concepts in connection with the progression of the technological knowledge, and the former conceptual entities within the discipline have been evolved accordingly (Yazıc1, 2007, p.7).

This study argues whether the translation teaching is on a journey from inter-disciplinarity to trans-disciplinarity. The reason is that new technological tools have now replaced the paper based tools (e.g dictionaries) and other old fashioned instruments (e.g type-writers and pencils which were previously often used in the translation process).Besides, it is a well-known fact that Translation Studies has long had a relationship with many disciplines such as literature, philosophy, sociology, psychology, history, linguistics, cultural studies and so forth. But it is now also claimed that it witnesses a technological turn (see Snell-Hornby, 2006; O'Hagan, 2013). The technological turn is a new, gradually popularized term within Translation Studies which consists new computer technologies, latest developments in the digital area and CAT tools such as translation memories, terminology management systems, quality assurance tools, translation project management tools which were highly neglected in the traditional translation (see Zhang and Cai, 2015, p.432). All these developments might be a clue to explain the trans-disciplinary journey of Translation Studies 
and of the translation teaching in parallel. To make the point clear, the study first explains inter-disciplinary and transdisciplinary concepts by referring to the technological progression within Translation Studies and the translation teaching. Secondly, it analyzes some translation courses which focus on translation technologies and it explains the position of the translation teaching in terms of the "trans-disciplinarity" concept.

\subsection{Objective of the Study \& Methodology}

This study has an intention to analyze technology related courses at three universities to show whether translation studies has a journey from inter-disciplinarity to trans-disciplinarity. In doing so, the aim is not to ignore interdisciplinary bounds of translation studies with other disciplines but to show the increasing presence of transdisciplinary studies and research (see also Yazıc1, 2011) within TS. For this, the study follows a descriptive analysis ${ }^{\mathrm{ii}}$.

\section{Interdisciplinarity \& Trans-disicplinarity Concepts within Translation Studies and Translation Teaching}

Interdisciplinarity concept brings to the mind the relationship with two or more disciplines. It generally includes knowledge, research, education and theory. All these four realms of inter-disiplinarity (see also Şan, 2014) are concerned with the relationship between two or more disciplines (Nissani, 1997, p.1). The translation phenomena, though it is as old as the history of mankind, was only accepted as a discipline in the second half of the twentieth century. However, as stated before, it later established a connection with other disciplines, which makes it an interdisciplinary field. So the translation teaching was updated according to the new status.

The trans-disciplinarity, on the other hand, can be defined as the transgression of borders. The terms does not deny the existence of the previous disciplines. Instead, it embraces the new ones. According to Nowotny, the term is "more than juxtaposition; more than laying one discipline along side another" (see Nowotny; see Odacığlu\& Köktürk, 2015). We can therefore associate Translation Studies and the translation teaching with trans-disciplinarity concept as well because the translation market is currently needs driven and in parallel, demands for translation generally come from software\&hardware companies and technology manufactures, all of which enable the translation field to integrate itself with the Information and Communication technologies in general. In doing so, we never reject the inter-disciplinary characteristics of Translation Studies but it is obvious that the translation discipline now transgresses the former borders and moves towards new areas based on technological developments.

In connection with the previous paragraph, especially the localization industry being popularized as of 1990s due to the widespread use of computers among ordinary people has accelerated the transgression of borders within Translation Studies and the translation teaching. From this point on, it is not enough for translation students to have a good command of their native and the second or even the third languages because they do not only transfer language and culture in the translating process but they also are responsible for the technological transfer. Besides, even if they might not fluently speak foreign languages or write them correctly, translators can do acceptable translations thanks to the technological tools in the translation process. Therefore, what is expected of them besides knowing a second or third language is to be expert at using computer with all of its components during the process. In parallel, courses requiring the use of the technology must be increased in the translation currciula because today most of the translation jobs come from the localization market.

It would also be useful to refer to Kiraly's concept of social constructivism, constituting a paradigm shift in the education methodology within Translation Studies. Social constructivism defends that individual students construct knowledge collectively in a team, which implies a collaboration in the translation process. As the knowledge, to Kiraly, is collected mutually, this new way of teaching enables a more active translation process than the transmission approach in which the authority is in the hands of a teacher. In social constructivism, the role of the teacher is however only to guide the students so that they can follow their own learning processes (see Pym, 2011, p.318, Odacioğlu and Köktürk, 2015) $)^{\mathrm{iii}}$. Finally, it is believed that the functionality of the social constructivist approach can be achieved only if the transgression of the borders within Translation Studies or in other words the transdisciplinarity is discussed under Translation Technologies or the digital revolution.

\section{Analysis of the Technology Based Translation Courses at Boğaziçi, Illinois and Western Sydney Universities in terms of Trans-Disciplinarity Concept}

In this part, technology based translation courses at three universities which have been chosen for the study are presented with their contents and course codes to question whether they might be associated with trans-disciplinary characteristics of Translation Studies and the translation teaching. In this way, it is also intended to prove the presence of the trans-disciplinary research (see also Yazıc1, 2011) and entities within both the discipline and the translation teaching.

Table 1. Boğaziçi University Translation Studies Undergraduate Program iv

\begin{tabular}{lll}
\hline Course Code & Course Name & Course Content \\
\hline TR 203: Third & Information Technologies & "Introduction to information technologies developed for \\
Semester & (IT) for Translators & $\begin{array}{l}\text { translators and language professionals. Focus on major } \\
\text { language-related technologies and their historical } \\
\text { (Second Year, }\end{array}$
\end{tabular}



processors and translation memory software. Discussion on benefits, uses and limitations of existing technologies. Ethical issues. Overview of current research.."

\begin{tabular}{lll}
$\begin{array}{l}\text { TR 208 } \\
\text { (Second Year, } \\
\text { optional) }\end{array}$ & Localization & $\begin{array}{l}\text { "Basic guidelines to localization, history of localization } \\
\text { industry and its present state. General introduction to and } \\
\text { hands on practice with translation memory. Terminology } \\
\text { tools, software localization, project management. } \\
\text { Prerequisite: TR 203"vi }\end{array}$ \\
\hline $\begin{array}{l}\text { TR 215: Third } \\
\text { Semester }\end{array}$ & Technical Translation & $\begin{array}{l}\text { "Practice with texts related to science, technology, } \\
\text { (emphasis intentional) law, and medicine. Basic }\end{array}$ \\
(Second Year, & & $\begin{array}{l}\text { terminology. Theoretical approaches to technical } \\
\text { Compulsory) }\end{array}$
\end{tabular}

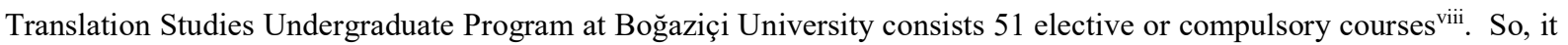
can be said that courses cover a wide range of topics or translation types from etymology, language of journalism, theories of translation, intercultural communication studies, medical translation, literary translation, translation criticism, translation history to the translation of EU texts, semiotics, translation of social sciences, translation of prose fiction, poetry translation, interpreting, Japanese culture in translation and so forth ${ }^{\mathrm{ix}}$. The courses on these topics or translation types prove the inter-disciplinary aspects of Translation Studies and of the translation teaching if their contents are checked carefully. However, as can bee seen in Table I, Boğaziçi University has also begun offering two compulsory and one elective courses titled "Information Technologies (IT) for Translators" (TR 203), "Localization" (TR 208) and "Technical Translation" (TR 2015) all of which focus directly or indirectly on the teaching of communication and information technologies, the translation technologies, translation memory softwares, terminology tools and localization. This development shows that the current borders of Translation Studies and the translation teaching extend into new fields of study, research or translation. This can be a concrete example of a journey from interdisciplinarity to trans-disciplinarity within Translation Studies and the translation teaching as the current borders are transgressed by the new ones which foreground the technology phenomena. So, the content of the analyzed courses can be said to have been designed by taking into account the recent developments.

Table 2. University of Illinois Center for Translation Studies Undergraduate Program ${ }^{\mathrm{x}}$

\begin{tabular}{|c|c|c|}
\hline Course Code & Course Name & Course Content \\
\hline TRST 406 & $\begin{array}{l}\text { Translation for the } \\
\text { Professions }\end{array}$ & $\begin{array}{l}\text { "Develop the practice of "instrumental" translation skills in } \\
\text { a variety of technical domains, including translation for new } \\
\text { media, medical and legal translation, and localization. } \\
\text { Focuses on the technical, cultural and terminological } \\
\text { problems that characterize localization and globalization as } \\
\text { governing criteria of translation in today's knowledge } \\
\text { economy. } 3 \text { undergraduate hours. } \\
\text { Prerequisite: Departmental approval. Six semesters of } \\
\text { foreign language study".xi }\end{array}$ \\
\hline
\end{tabular}

\begin{tabular}{lll}
\hline TRST 407 Terminology & and & "The theoretical and practical aspects of terminology \\
Computer-Assisted & studies, as well as the computer skills required of a \\
Translation (CAT) & translator in today's Language Service Provider (LSP) \\
& environment, mastery of a variety of computer-assisted \\
& translation (CAT) tools and the SDL Trados suite. Practical \\
& applications of terminology work include advanced Internet \\
& research for translation work, terminology "mining" \\
& exercises, construction of terminology databases and \\
& management of those databases. Terminology theory is \\
& situation within the field of Translation Studies as derived \\
& from the discipline of linguistics. 3 undergraduate hours \\
& Prerequisite: Departmental approval."
\end{tabular}

\begin{tabular}{lll} 
TRST 408 CAT Tools: Translation & "This is an advanced tools course that focuses on in-depth \\
& Tools and Practice & $\begin{array}{l}\text { familiarity with a range of CAT tools and also localization } \\
\text { software. It combines the most up-to-date theoretical studies }\end{array}$ \\
\hline
\end{tabular}


on translation/localization practices with hands-on activities aimed at having students understand and reflect, by using the tools, on the language-, culture- and content-bound issues that translation professionals face when adapting content from an L1 to an L2 culture. Among the tools that will be used in class and for assignments are WinAlign \& Paraconc (Alignment tools), AntConc \& SCP (Simple Concordance Program) (Concordance tool), SDL Trados Studio \& MemoQ (TM creation \& Translation), MultiTerm Extract \& Multiterm (Terminology mining), SDL Passolo (Software localization), and Systran \& Google Translate (Machine Translation). The class will be structured into three main units: Corpus Generation, Website/Software Localization and Machine Translation. 3 undergraduate hours.

Prerequisite: Departmental approval."'xiii

TRST $420 \quad$ Translation Practice "Introduction to a variety of issues focused on how to approach translation projects including a study of text types and genres, the formal properties of texts, grammatical and syntactical issues of translating, questions of linguistic register, considerations of the target audience, the meaning of "localization", cultural and ethical concerns and strategies of compensation. The importance of studying a text and making strategic decisions before starting a translation will be emphasized and discussed, as well as the crucial step of revising and editing the translated text. 3 undergraduate hours..

Prerequisite: Departmental approval. Six semesters of foreign language study."

Center for Translation Studies Undergraduate Program at University of Illinois has nearly ${ }^{\mathrm{xv}} 16$ courses on the translation EU texts, bilingualism, commercial and technical translation, translation theory\&practice, Spanish/English translation, Arabic/English translation, Chinese Poetry and translation, history of translation and Russian translation, etc $^{\mathrm{xvi}}$. The topics covered for the courses are apparently various and they can be a determinant factor for translation students to decide at which field they might be an expert at the end of the undergraduate program. These courses can implicitly reveal the inter-disciplinary characteristics of Translation Studies and the translation teaching. Courses shown in Table 2, on the other hand, might be the examles of trans-disciplinary aspects of Translation Studies and the translation teaching. Ther first course, entitled "Translation for the Professions" (TRST 406) deals with many translation fields like medical, media and legal translation as well as an emerging concept known as localization within TS. Especially the localization requires would-be translators to have a good command of software applications, computerized tools and computer technologies in general. Therefore, the fact that this translation modality is presented under this course is of utmost importance to catch the needs driven localization/translation market. It should at this point be remembered that the duty of the translator is now not only translating but they must also be a good language engineer, reviser, terminology expert and a new sort of job, localization engineer to be able to separate translatable strings from the source code (see Esselink, 2002). Similarly, "Terminology and Computer-Assisted Translation (CAT") course enables would-be translators to understand the logic behind CAT tools like translation memory tools. To this end, it mainly focuses on SDL Trados suite. Besides, the course may show how translation students can conduct resarch on internet or how they construct terminology databases and manage them, etc. All of these updates in the translation teaching actually may show the transgression of the current borders and it may be an example of a transdiciplinary approach.

The last course chosen for the study has a title of "Translation Practice" (TRST 420). It focuses on text types, genres, grammatical and syntactical issues of translation, linguistic register, target audience, cultural and ethical issues, strategies of compensation and the decision to be applied during the translating process and also localization. The fact that the course also touches on the localization concept may show likewise the transgression of borders towards new horizons in which technology is stressed. Therefore, it may also an example of a trans-disciplinary journey within Translation Studies and the translation teaching. 
Table 3. Western Sydney University Interpreting and Translation Undergraduate Program ${ }^{\text {xvii }}$

Course Code Course Name Course Content

101302.2 Translation Technologies

(Year 3, Spring

Session)
"This unit aims to equip students with the theoretical and practical knowledge needed to effectively apply information and communication technologies to translation and other language related tasks. It focuses on translation memory and terminology management systems, and on the workflow involved in the handling of multilingual content. Emphasis is also put on uses of the Internet as a resource tool, and to the principles of controlled language for text to be processed by machine translation (MT). Tutorials will be conducted in a computer lab where students will familiarize themselves with leading computer-assisted translation (CAT) software applications." ${ }^{\text {xviii }}$

Interpreting and Translation Undergraduate Program at Western Sydney University consists almost 57 courses ${ }^{\text {xix }}$ which is about analytical reading and writing, Australia history, interpreting, texts and traditions, linguistics, community translation, text and discourse in English, behaviour and environment, bilingualism and biculturalism, translation professional practicum, legal interpreting, semantics and pragmatics, medical interpreting, second language acquisition, sociolinguistics, advanced writing skills, Arabic language, Chinese language, Japanese language, Spanish language, inter-cultural pragmatics, world cinema, world literature in translation and like ${ }^{\mathrm{xx}}$. Especially the variety of languages included in the translation curricula show that the multilingualism and multiculturalism are heavily taught in some of the courses in the depmartment. Besides, the presence of such courses indicates the inter-disciplinary aspects of the translation teaching, therefore they can be good examples to conduct inter-disciplinary resarch within Translation Studies as well the teaching of translation. However, a course entitled “Translation Technologies" (101302.2) presents a different dimension in that it refers to the information and communication technologies, translation memory and the translation management systems, machine translation, main software applications used in the translation process and an umbrella the term internet having new cloud based applications. These may show that the traditional way of translation is transgressed in this course because the translational activity is carried out using databases or new sort of technological tools. Because of this, what this course probably presents is trans-disciplinary approach to the translation practice or the trans-disciplinary research within Translation Studies and the translation teaching.

\section{Conclusion}

The analysis of some technology based translation courses offered by Translation Studies or Translation \& Interpreting departments of Boğazçi, Illinois and Western Sydney Universities shows that Translation Studies and the translation teaching has begun a journey from inter-disciplinarity to trans-disciplinarity. The term trans-disciplinarity here summarizes the transgression of the available borders within this field. The available borders within Translation Studies and the translation teaching are generally formed by literary and cultural studies, linguistics, philology, sociology, philosophy and so forth. However, the courses shown in each table with their detailed contents bring to the mind new fields or borders to begin a new journey in accordance with today's modern conditions. So, courses including the teaching of translation tehnologies, localization, CAT tools such as translation memory systems, terminology management systems an so forth can be correlated with trans-disciplinary characteristics of Translation Studies and the translation teaching. Besides, these courses are generally reinforced with the teaching of the communication and information technologies so that would-be translators can, in their first steps, be used to the computerized settings requiring the use of new digital tools such as the ones mentioned above instead of using old fashioned paper based dictionaries and typewriters.

\section{References}

Esselink, B. (2002). Localization Engineering: The Dream Job. Traduccio i Technologies Informacio i la Communicacio Numero 1:La Localització: Octubre 2002:

http://www.raco.cat/index.php/Tradumatica/article/viewFile/29123/28959 02.09.2015.

Nissani, M. (1997). Ten Cheers for Interdisciplinarity: The Case for Interdisciplinary Knowledge and Research,.The Social Science Journal, Volume 34, Number 2, 201-216.

Nowotny, H. (2006). The Potential of Transdisciplinarity, http://www.helganowotny.eu/downloads/helga_nowotny_b59.pdf. Accession:12.05.2015.

Odacıoğlu, M.C and Köktürk, Ş. (2015). From Interdisciplinarity to Transdisciplinarity in Translation Studies in the Context of Technological Tools \& Localization Industry. International Journal of Comparative Literature \& Translation Studies IJCLTS , 3:3, p.14-19.

Odacıŏlu, M.C ve Köktürk., Ş. (2015). A Paradigm Shift in Academic Translation Teaching and Its Reflections on the Localization in the Digital Age. Journal of Language Teaching and Research, p.1175-1180. 
O, Hagan, M. (2013). The Impact of New Technologies on Translation Studies: A Technological Turn?. The Routlege Handbook of Translation Studies, (eds. Carmen Millán and Francesca Batrina). P. 503-517. London and New York: Routledge.

Pym, A. (2011). Training Translators. The Oxford Handbook of Translation Studies, (eds. Kirsten Malmkjaer and Kevin Windle) p.313-321, Oxford University Press.

Snell-Hornby, M. (2006). The Turns of Translation Studies,Amsterdam and Philadelphia: John Benjamins Publishing Company,

Şan, F. (2014). Disiplinelerarasılık Açısından Bir Bilim Dalı olarak Çeviri (Translation Studies in terms of Interdisciplinarity), PHD Thesis, Sakarya University: Intitute of Social Sciences.

Yazıcı, M. (2007), Çeviribilimde Araştırma (Research in Translation Studies), İstanbul: Multilingual.

Yazıcı, M. (2011), Yazılı Çeviri Edinci,İstanbul: Multilingual.

Zhang, C. and Cai, H. (2015). On Technological Turn of Translation Studies: Evidences and Influences, Journal of Language Teaching and Research, (6:2), p.429-434.

http://www.transint.boun.edu.tr/?q=en/node/13Accession:26.10.2015.

http://www.translation.illinois.edu/courses.htmlAccession:26.10.2015.

http://handbook.uws.edu.au/hbook/course.aspx?course=1519.4Accession:15.10.2015.

\section{Notes}

${ }^{\mathrm{i}}$ Localization for instance, as a kind of a specialized translation or a new sub-branch can be added into the applied translation studies category.

ii The aim, when choosing these three universities for the study is not to compare them to each other in terms of their positive or negative aspects but to find out the presence of technology related courses in translation curricula and to analyze whether these courses contribute to the trans-disciplinary aspects of Translation Studies \& Translation Teaching or not.

iii The effect of social constructivism (occuring in the translation teaching) is discussed by Odacioğlu and Köktürk on the localization industry to question whether this industry can also be a paradigm within Translation Studies or not in their articles named A Paradigm Shift in Academic Translation Teaching and Its Reflections on the Localization in the Digital Age (2015).

${ }^{i v}$ http://www.transint.boun.edu.tr/?q=en/node/13Accession: 26.20 .2015

Vhttp://www.transint.boun.edu.tr/?q=en/node/13Accession: 26.20.2015.

${ }^{v i h t t p: / / w w w . t r a n s i n t . b o u n . e d u . t r / ? q=e n / n o d e / 13 A c c e s s i o n: ~ 26.20 .2015 . ~}$

viihttp://www.transint.boun.edu.tr/?q=en/node/13Accession: 26.20.2015.

viiihttp://www.transint.boun.edu.tr/?q=en/node/13Accession: 27.10.2015

${ }^{\text {ix }}$ For detailed information, the website of the university is http://www.transint.boun.edu.tr/?q=en/node/13

${ }^{x}$ http://www.translation.illinois.edu/courses.htmlAccession: 26.10.2015..

xihttp://www.translation.illinois.edu/courses.htmlAccession: 26.10.2015.

xiihttp://www.translation.illinois.edu/courses.htmlAccession: 26.10.2015.

xiiihttp://www.translation.illinois.edu/courses.htmlAccession: 26.10.2015.

${ }^{\mathrm{xiv}} \mathrm{http}$ ://www.translation.illinois.edu/courses.htmlAccession: 26.10.2015.

${ }^{\mathrm{xv}} \mathrm{http}$ ://www.translation.illinois.edu/courses.htmlAccession: 27.10.2015.

${ }^{x v i} \mathrm{http}: / / \mathrm{www}$. translation.illinois.edu/courses.htmlAccession: 28.10.2015.

xvii http://handbook.uws.edu.au/hbook/course.aspx?course=1519.4Accesion: 15.10.2015.

xviiihttp://handbook.uws.edu.au/hbook/course.aspx?course=1519.4Accesion: 15.10.2015.

${ }^{\mathrm{xix}} \mathrm{http}$ ://www.translation.illinois.edu/courses.htmlAccession: 27.10.2015.

${ }^{\mathrm{xx}} \mathrm{http} / /$ handbook.uws.edu.au/hbook/course.aspx?course=1519.4Accession: 15.10.2015. 